\title{
Diet and Activity Budget in Colobus angolensis ruwenzorii at Nabugabo, Uganda: Are They Energy Maximizers?
}

\author{
T. Jean M. Arseneau-Robar ${ }^{a}$ Amtul H. Changasi ${ }^{a}$ Evan Turner ${ }^{b}$ \\ Julie A. Teichroeb ${ }^{\text {a }}$ \\ ${ }^{a}$ Department of Anthropology, University of Toronto Scarborough, Toronto, ON, Canada; ${ }^{b}$ Department of Health \\ Sciences, Faculty of Science, Carleton University, Ottawa, ON, Canada
}

\section{Keywords \\ Colobines · Diet composition · Food selection · Group cohesion · Fallback foods}

\begin{abstract}
Introduction: Colobine monkeys are specialized folivores that use foregut fermentation to digest leaves. The slow process of fermentation forces them to spend a lot of time resting and to minimize their energy expenditure to subsist on a lower-quality diet. Methods: We recorded the diet and activity budget of Colobus angolensis ruwenzorii, which form a three-tiered multi-level society, at Lake Nabugabo, Uganda, over 12 months using scan sampling on adults and subadults, to determine whether they utilize the energy minimization strategy typical of colobines. Results: We found that the annual diet was primarily comprised of high-quality food resources (young leaves $65 \%$ and fruit 31\%), and fruits were the only plant part the monkeys selected when available. Both the fruits and young leaves of some species were preferred food items in some months, and mature leaf consumption correlated negatively with preferred food availability. Mature leaves appear to be a fallback food for this population but are rarely relied upon (3\%). The C. a. ruwenzorii at Nabugabo spent less time resting (40\%) and more
\end{abstract}

karger@karger.com www.karger.com/fpr

Karger $\stackrel{\text { ' }}{5}$

GOPEN ACCESS
(C) 2020 The Author(s)

Published by S. Karger AG, Basel

This is an Open Access article licensed under the Creative Commons Attribution-NonCommercial-4.0 International License (CC BY-NC) (http://www.karger.com/Services/OpenAccessLicense), applicable to the online version of the article only. Usage and distribution for commercial purposes requires written permission. time moving (25\%) than is typical for other species of blackand-white colobus. Discussion/Conclusion: The high-quality diet of this population appears to allow them to utilize an energy maximization strategy. Their reliance on food items that tend to be clumped in space and time likely explains the frequent fission-fusion behaviour that we observe between core units. Our findings demonstrate that the foraging strategies of colobines may be more flexible than was previously thought and illustrate how food availability and distribution can impact primate social organization.

(c) 2020 The Author(s)

Published by S. Karger AG, Basel

\section{Introduction}

Primate fitness is heavily influenced by diet [Altmann, 1991, 1998], and therefore much of the variation in primate behaviour and morphology can be explained by the abundance, distribution, and quality of their food resources [Clutton-Brock and Harvey, 1977; Wrangham, 1980; Chapman and Chapman, 1990; Chapman et al., 2012]. Consequently, the last few decades have produced a body of research examining food selection and preferences in primates. These studies have largely focused on 
how the need to meet nutritional requirements is balanced with other necessary activities and how foraging strategies impact social systems [e.g., Garber, 1987; Ganzhorn, 1988; Kappeler and van Schaik, 2002; Felton et al., 2009; Lambert and Rothman, 2015].

Primate foraging decisions are greatly dependent on the nutritional value (e.g., protein, carbohydrate/sugar and lipid/fat content) of the food items available [Kumpan et al., 2019], as well as their physical and chemical defences. Physical defences make plants hard to process (e.g., thorns) or difficult to digest (e.g., fibre such as cellulose) [Waterman, 1984]. Chemical defences, also called secondary metabolites, can be distasteful (e.g., alkaloids), interfere with the efficiency of nutrient absorption and therefore inhibit digestibility (e.g., tannins), or be toxic (e.g., nicotine) [Griffiths, 1986; Waterman and Kool, 1994]. The concentration of secondary metabolites and the nutritional content both vary with the part of the plant that is being consumed, as well as its stage (e.g., ripeness or maturity) [Lambert and Rothman, 2015; reviewed by Garber, 1987]. For example, leaves tend to be a good source of protein [Ganzhorn et al., 2017] but also contain fibre and secondary metabolites, with the highest levels of these occurring in mature leaves [Waterman et al., 1980; Coley and Barone, 1996]. Fruits are high in sugar, particularly when they are ripe, seeds are a good source of protein and fat, and bark is primarily fibre [Lambert and Rothman, 2015]. Lichens are generally a poor source of protein, sugar and fat, but are used by some species as a seasonal fallback food [Liu et al., 2013; Grueter et al., 2009].

A number of foraging strategies have been proposed to explain what food items are selected and the quantity of each that are consumed [reviewed by Felton et al., 2009]. The foraging strategy a species utilizes has important consequences for the ways in which they allocate their time. Energy maximization strategies are often considered under optimal foraging theory and posit that individuals try to maximize their energy obtained per unit feeding time [Emlen, 1966; Schoener, 1971]. Primate species that are largely frugivorous are often thought to employ this strategy. Because fruits tend to occur in discrete clumps, frugivores typically spend more time moving and travel further between food patches, spend more time searching for and feeding on fruits, and spend comparatively little time resting [Rosenberger and Strier, 1989; Strier, 1992; Korstjens et al., 2010; Fashing, 2011]. Conversely, folivores are often thought to employ an energy minimization strategy [Dasilva, 1992; Wasserman and Chapman, 2003; Rangel-Negrín et al., 2018; Klass, 2020].
Many folivores have evolved specialized guts to optimize their digestion of leaves [Ankel-Simons, 2007]. In the case of colobines, this is a foregut fermentation system that allows them to neutralize some of the toxins present in their food and process energy from leaves high in fibre [Bauchop and Martucci, 1968; Chivers, 1994; Kay and Davies, 1994]. However, the slow process of fermentation, and the associated problem of gut fill, results in high levels of forced resting time, necessitating an energy minimization strategy [Oates, 1977; Dasilva, 1992; Dunbar, 1992; Strier, 1992; Korstjens et al., 2010]. Consequently, highly folivorous species tend to spend more time resting than frugivores [Rosenberger and Strier, 1989; Strier, 1992; Korstjens et al., 2010; Fashing, 2011]. Furthermore, because leaves tend to be uniformly distributed, folivores are able to spend less time moving and searching for food [Isbell, 1991]. While these general patterns exist between folivores and frugivores, groups may adjust their time budgets and movement patterns, depending on the availability of different food items and their distribution [Godfrey, 2003; Riley, 2007; Dunbar et al., 2009], with the same species showing an energy minimization strategy in one habitat and an energy maximization strategy in another [Alouatta calmitans, Jung et al., 2015; A. pigra, RangelNegrín et al., 2018; Klass, 2020; A. palliata mexicana, Asensio et al., 2007; Chlorocebus djamdjamensis, Mekonnen et al., 2017].

The African colobines are largely considered to be folivorous, although the percentage of leaves in the diet varies both between and within species [Fashing, 2011]. This dietary flexibility is thought to allow for a large amount of lability in their social systems [Fashing, 2011]. In general, the red colobus (Piliocolobus spp.) consume more fruit than the other African colobines and live in larger groups (i.e., 15-75 individuals on average) [Korstjens and Dunbar, 2007]. Olive colobus (Procolobus verus) and most black-and-white colobus (Colobus spp.) are similar in that they tend to be more folivorous than red colobus and live in relatively small groups (i.e., 4-20 individuals on average) [Oates, 1988; Korstjens, 2001; Korstjens and Dunbar, 2007]. A striking exception to this pattern is Colobus angolensis, in which the Rwenzori subspecies can form groups that are extremely large. In the high-altitude forest of Nyungwe National Park (Rwanda) groups contain 300-500 individuals [Fimbel et al., 2001; Fashing et al., 2007; Miller et al., 2020c]. Although these groups are organized into multi-level societies [Miller et al., 2020c], groups are fairly cohesive [Fimbel et al., 2001; Fashing et al., 2007; Miller et al., 2020c]. Recent work from a mid-altitude forest at Lake Nabugabo (Uganda)
36

Folia Primatol 2021;92:35-48 DOI: $10.1159 / 000511046$
Arseneau-Robar/Changasi/Turner/ Teichroeb 
has found C. a. ruwenzorii aggregations of approximately 200 individuals also form a multi-level society, but groups are not cohesive, rather core units fission and fuse throughout the day [Stead and Teichroeb, 2019].

To date, C. a. ruwenzorii foraging strategies have only been studied at Nyungwe, where it is thought that they are able to live in a large and relatively cohesive society because they have access to an abundant, high-quality food resource [Fimbel et al., 2001; Fashing et al., 2007]. Here, their diet is primarily comprised of young and mature leaves (25 and 40\%, respectively) [Fimbel et al., 2001], which is one of the highest documented levels of folivory among the Colobinae [Oates, 1977; Wasserman and Chapman, 2003; Saj and Sicotte, 2007a; Fashing, 2011]. However, the mature leaves at this high-altitude site are richer in protein and lower in fibre than has been observed at other black-and-white colobus field sites. When leaves are in low supply, the monkeys can fall back to feeding on lichens, which are also abundant [Miller et al., 2020a]. While other African colobines that are highly folivorous tend to dedicate much (i.e., $>50 \%$ ) of their time to resting [reviewed in Fashing et al., 2007; Fashing, 2011], C. a. ruwenzorii in Nyungwe spend only $32 \%$ of their time resting [Fashing et al., 2007]. Thus, this population does not seem to employ the energy minimization strategy typical of other highly folivorous black-and-white colobus [Fashing et al., 2007]. The low resting time seen in this population is suggested to be a manifestation of scramble competition, as so many individuals foraging together drives up search times and necessitates increased travel to find food [Fashing et al., 2007]. Indeed, scramble competition, inferred using patch depletion, appears to be an issue for this population for most food types with the exception of mature leaves [Miller et al., 2020b].

It is still unknown how generalizable an energy maximization foraging strategy is to other C. a. ruwenzorii populations and/or subspecies since $C$. angolensis is not well studied. It has been noted that $C . a$. cottoni in the Ituri Forest, DRC, are unusually active compared to other colobus monkeys [Bocian, 1997], which hints that this may be a species-wide pattern of behaviour. The goal of this study is to examine the diet and activity budget of $C$. a. ruwenzorii living in the mid-altitude forest at Nabugabo, Uganda, in order to determine the foraging strategies employed by this population. The habitat use of the Nabugabo population differs greatly from the Nyungwe population owing to differences in the availability of food at various forest strata and differences in the complement of predators [Adams and Teichroeb, 2020]. Although not as large as the group sizes observed in Nyungwe, bands of

Rwenzori Colobus Diet and Activity Budget
C. a. ruwenzorii at Lake Nabugabo are much larger than the group sizes observed in most black-and-white colobus. Therefore, we hypothesize that this population must also have access to abundant, high-quality food resources. Without nutritional analyses to confirm food quality, it is likely that high-quality resources at this lower altitude site will follow common patterns and consist of young leaves, seeds, or fruit, which are items that tend to be high in protein and carbohydrates but low in fibre [Lambert and Rothman, 2015; Ganzhorn et al., 2017]. To verify this supposition, we examined the extent to which these plant parts were consumed relative to their availability, and the extent to which C. a. ruwenzorii preferred these plant parts for each species present in their diet. We expect that the diet of the C. a. ruwenzorii at Nabugabo will largely consist of these high-quality, preferred foods. We also hypothesize that a high-quality diet will allow the C. $a$. ruwenzorii at Lake Nabugabo to employ an energy maximization foraging strategy. Therefore, we expect to see levels of resting time that are similar to those observed at Nyungwe [30-40\%; Fashing et al., 2007] and lower than is typical of other black-and-white colobus species [ $>50 \%$; Fashing et al., 2007; Fashing, 2011]. Lastly, because there are known differences in group cohesion between the two sites, we do expect to see some differences in foraging strategies of the C. a. ruwenzorii at Nabugabo versus Nyungwe. The higher levels of group cohesion at Nyungwe are thought to be possible because both the preferred and fallback foods of the C. a. ruwenzorii at this site are abundant and uniformly distributed [Fimbel et al., 2001; Fashing et al., 2007], and therefore able to support large aggregations of animals [Janson and van Schaik, 1988; Johnson et al., 2002]. We hypothesize that the greater propensity for core units to fission and fuse at Nabugabo [Stead and Teichroeb, 2019] arises because they primarily consume foods that occur in a clumped distribution, and that these cannot always support large groups, necessitating group fission [Wrangham and White, 1988; de Sá and Strier, 1992; Asensio et al., 2007]. Therefore, we expect that both the preferred and fallback foods of the $C$. a. ruwenzorii living at Nabugabo will primarily consist of items such as fruits, seeds, or young leaves [Janson and van Schaik, 1988; Johnson et al., 2002].

\section{Methods}

Study Site and Species

Data for this study were collected on Rwenzori Angolan colobus monkeys (Colobus angolensis ruwenzorii) on the western edge of Lake Nabugabo, a small lake $(8.2 \times 5 \mathrm{~km}$, elevation $1,136 \mathrm{~m})$ ly- 


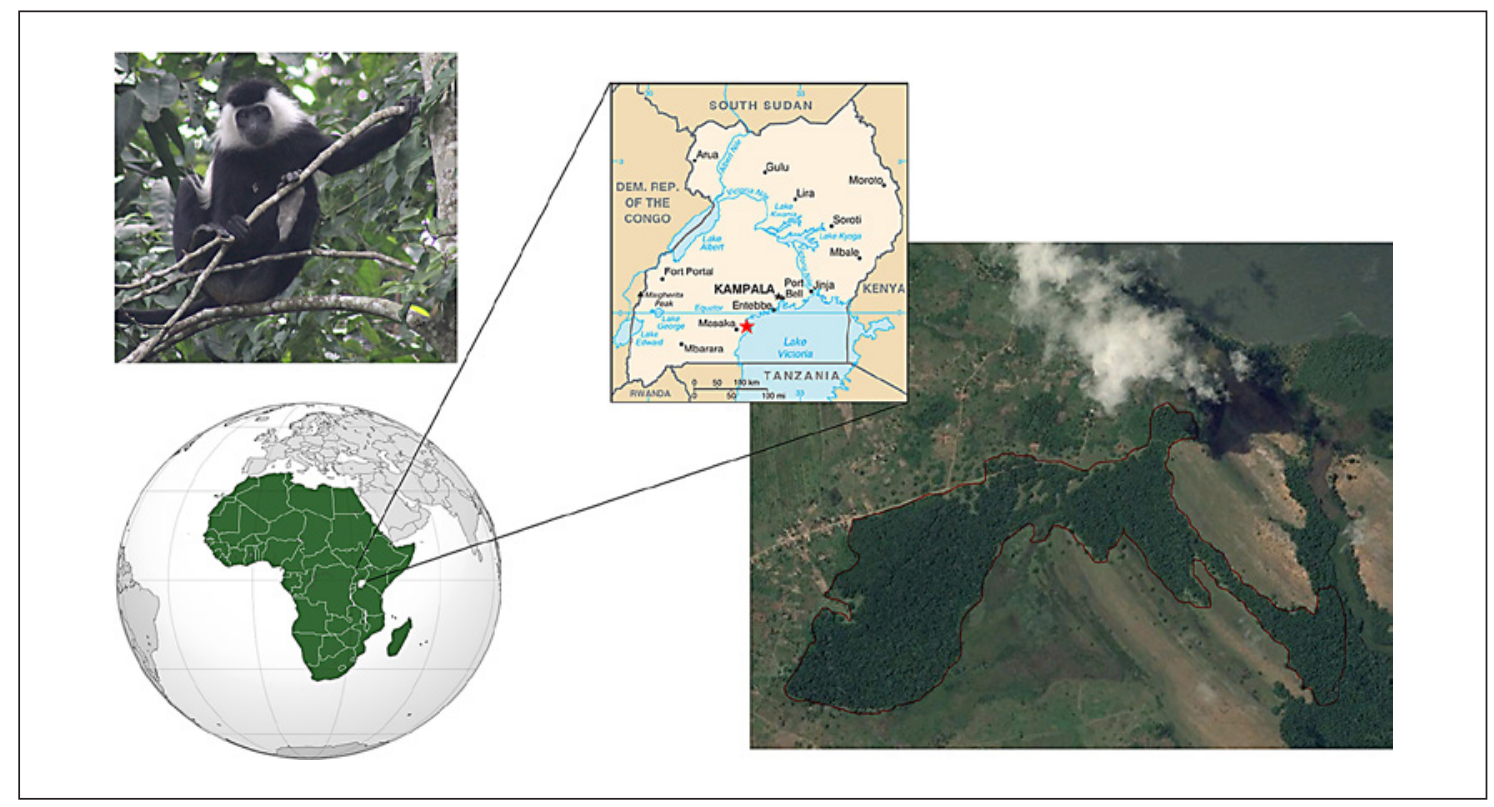

Fig. 1. The location of Uganda in Africa and the location of Lake Nabugabo in Uganda indicated by the red star. The satellite images show the forest fragment where the study band of Colobus angolensis ruwenzorii live with their home range outlined in red. The photo is of an adult female C. a. ruwenzorii (photo by Julie Teichroeb). Satellite image (Google Earth, 2018).

ing just west of Lake Victoria in central Uganda $\left(0^{\circ} 22^{\prime}-12^{\circ} \mathrm{S}\right.$ and $\left.31^{\circ} 54^{\prime} \mathrm{E}\right)$ (Fig. 1). The landscape is a mixed habitat of wetlands, grasslands, patches of primary and secondary forest, degraded forest, farmers' fields, and a few buildings [Chapman et al., 2016]. There are two peaks in rainfall over the year from February to May and September to November, and the mean annual rainfall over a 5 -year period was $1,117.21 \mathrm{~mm}$ (SD \pm 729.46$)$ (2015-2019). The average temperature over the same 5 -year span was $21.96^{\circ} \mathrm{C}$ (SD \pm 1.21 ) (data from www.worldweatheronline.com for the nearby town (12.5 km away) of Masaka). The colobus monkeys were followed in a primary and secondary forest fragment, which is made up of the approximately 280-ha Manwa Forest Reserve and an unprotected forest fragment that borders the Juma River [Teichroeb et al., 2019]. Potential predators of the colobus consisted of venomous and constricting snakes (e.g., Dendroaspis polylepis, Dispholidus typus, Python sebae), crowned hawk eagles (Stephanoaetus coronatus), and local people's dogs (Canis lupus familiaris) [Adams and Teichroeb, 2020].

We studied one large band of C. a. ruwenzorii (Band TR: approx. 120 individuals at the time of data collection) made up of 12 core units, of which 5 were uni-male/multi-female and 7 were multi-male/multi-female. We began following this band in 2015, and animals were well habituated. In the multi-level society that this species forms, there are at least three tiers of organization. Stable core units cluster into clans, and clans cluster together to share a home range in a band tier of organization. Core units fission and fuse with one another throughout the day, so although each core unit typically contains between 4 and 23 individuals, operational group size is often larger [Stead and Teichroeb, 2019]. No all-male unit was present during data collec- tion for the current study but they do sometimes occur in the population [Adams and Teichroeb, 2020]. Preliminary findings suggest that while both sexes disperse, males tend to disperse within bands while females disperse between bands [Stead and Teichroeb, 2019]. Consequently, female-female bonds tend to be weaker than in other black-and-white colobus species [Arseneau-Robar et al., 2018].

\section{Behavioural Data Collection}

Diet and activity budget data were collected by a team of two field assistants (E. Mujjuzi and H. Kaketo) over 12 months, between May 2016 and April 2017 (mean 10.8 days per month, range: 5-14 days; mean $79.7 \mathrm{~h} /$ month). Field assistants were trained by J.A.T., and the same two observers collected data together throughout the data collection period and agreed on categories before recording them. Follows generally began at 07:30 and continued until 16:30. Sunrise at Nabugabo occurs just before $07: 00$, so the assistants usually began collecting data when the colobus were still resting in their sleeping trees. One caveat of our study is that assistants left the study band about $2 \mathrm{~h}$ prior to sunset. Thus, they likely missed at least one bout of each feeding, resting, and movement, which could have impacted the proportions in our calculated activity budget. Field assistants collected instantaneous scan samples [Altmann, 1974] via the "frequency method" [Struhsaker, 1975] every $30 \mathrm{~min}$, on up to 5 individuals ( $n=9,373$ scans). Observers recorded each individual's age-sex class, identity (if known), activity state (e.g., feeding, moving, resting, social, or other), and a GPS location was taken. When feeding, the food item (i.e., young leaf, mature leaf, fruit, flower, seed, seed pod, etc. - see below for definitions of 
food items) and plant species were also noted ( $n=2,277$ feeding scans). Observers made an effort to move around the group between scans so that the same individuals were not scanned within the same 2 -h period. In addition, observers swept through the visible individuals from left to right to avoid scanning the same individual twice in the same scan. Any fission and fusion events with other core units were recorded ad libitum. When the core units being followed underwent fission, observers stayed with either the largest subgroup or the one that contained core units with the most known individuals.

When recording food item type, the age of leaves was determined by their colour and texture. Compared to mature leaves, young leaves were either a lighter green, red, or pink colour, appeared softer in texture, and occurred at the tips of branches. If leaf buds or flower buds were eaten, this was recorded. Fruit feeding was recorded when fruit flesh and smaller seeds within the flesh were fed upon. Seed eating was recorded if larger pits within fruits were consumed or if small seeds were extracted out of pods. If the whole seed pod was fed upon, seed pod feeding was recorded.

\section{Assessment of Food Availability}

We used a line transect survey carried out in the year before behavioural data collection to assess the species composition of the forest patch where the colobus reside. We mapped the perimeter of the forest fragment by walking around it with a GPS and then cut 32 parallel, straight-line transects at $100-\mathrm{m}$ intervals through the forest. Transects varied in length (range: 29-671 m) and were cut, either until the edge of the fragment was reached, or we moved into the swamp on the north-west side of the forest and standing water became more than $30 \mathrm{~cm}$ deep [Teichroeb et al., 2019]. To determine what tree species were available, we identified and measured all trees $\geq 10 \mathrm{~cm}$ diameter at breast height $(\mathrm{DBH})$ within $5 \mathrm{~m}$ on each side of transects. Trees were identified to the species level with the assistance of a knowledgeable local botanist (M. Ponsiano). For trees with multiple stems $\geq 10 \mathrm{~cm} \mathrm{DBH}$, we measured all stems and consolidated them by taking the square root of the sum of all squared DBHs [Nature Conservation, 2006]. On each transect, a scan was taken to assess average canopy height, and one tree that represented this height was measured using a clinometer. The total area sampled was 9.702 ha, which is $7 \%$ of the area covered by the forest fragment. Data from the ecological survey was used to determine the mean $\mathrm{DBH}(\mathrm{cm})$, stem density $(n / \mathrm{ha})$ and basal area $\left(\mathrm{m}^{2} / \mathrm{ha}\right)$ for each tree species. The basal area covered by each tree species was calculated by summing the area covered by each sampled tree $\left(\mathrm{A}=\pi \mathrm{r}^{2}\right)$ and dividing by the number of hectares sampled.

The seasonal availability of plant parts was recorded during monthly phenology surveys of 124 trees from 44 species, which pilot behavioural data had indicated were part of the colobus diet. We attempted a random sample of at least 3 individual trees of each species but not all 44 species had 3 individuals in the sample due to low availability. In addition, because the phenology survey was created before behavioural data collection began, lianas were not sampled, since it was not yet known how important they are in the diet. To ensure that phenology surveys were separated by a similar amount of time they were typically carried out in the middle of each month (range: the 11th to 18th day of the month). Observers used binoculars and indexed the approximate abundance of plant parts (i.e., flower buds and flowers, unripe and ripe seeds, unripe and ripe fruit, young leaves, mature leaves) by noting the percent of the canopy comprised of each part using a scale from 0 to 4 , where $0=$ the plant part is not present, $1=1-25 \%, 2=26-50 \%$, $3=51-75 \%$, and $4=76-100 \%$ [Sun et al., 1996]. For each tree species, phenology scores were averaged among all of the trees sampled in a given month. Food availability indices (FAI) were calculated for each plant part, each month, using the following formula, and summing the scores for all tree species [Fashing, 2001a; Dasilva, 1994]:

FAI $=$ average phenology score for species $\mathrm{i} \times$ basal area for species i.

\section{Data Analyses}

We calculated the proportion of the annual diet comprised of each tree species, as well as each plant part. Temporal patterns in diet were investigated by determining the proportion of the diet constituted by each plant part, each month. The average monthly rainfall was obtained from https://www.worldweatheronline.com/ for the nearby town of Masaka $(12.5 \mathrm{~km}$ away) and visually compared to phenological patterns. Activity budgets were calculated as the proportion of scans that individuals spent in each of the five behavioural categories (i.e., feed, rest, move, social, other), both annually and monthly. We determined the extent to which plant parts were selected relative to their availability by using Spearman rank correlations to compare the proportion of each plant part in the monthly diet to the food availability index for that plant part in that same month. To assess the extent to which each tree species was selected, we calculated selection ratios by dividing the proportion of each tree species in the annual diet by the proportion of the total basal area contributed by that species [Fashing, 2001a]. We calculated food preference scores for each part of each species using Ivlev's electivity index (EI) [Ganas et al., 2008; Watts, 1984]:

$$
E I=\frac{\text { monthly rank of that item in diet }- \text { monthly rank of availability of that item }}{\text { monthly rank of that item in diet }+ \text { monthly rank of availability of that item }} .
$$

In the rare cases where a part of a species was consumed but it did not appear in our phenology survey, we gave it an availability rank of "1" to indicate it was present but had low availability. Fallback foods are foods that are relied upon when preferred foods are scarce [Altmann, 1998; Doran-Sheehy et al., 2009]. We investigated the use of fallback foods using Spearman rank correlations to test for negative correlations between the consumption of potential fallback foods in the diet and the availability of (1) plant part(s) that were highly selected for or (2) the parts of species that were preferred in at least 1 month of the study period. In investigating fallback food use, we only considered plant parts that were important in the diet (i.e., $>1 \%$ of the annual diet). In all Spearman rank correlations, we present Monte-Carlo approximated $p$ values as these are more robust in the face of ties [Hájek et al., 1999], which occurred when rarely eaten plant parts comprised $0 \%$ of the diet in 2 or more months of the study period. Where appropriate we controlled for multiple comparisons using a Bonferroni correction to decrease the likelihood of false positives [Field et al., 2012]. Statistics were conducted using the "coin" package [Hothorn et al., 2006] in R [version 3.3.2; R Core Team, 2017] with R Studio version 1.1.463 [R Studio Team, 2020]. 
Table 1. Annual diet (\% of the annual diet) and activity budget (\% of the annual activity budget) for Colobus angolensis ruwenzorii living near Lake Nabugabo, Uganda

\begin{tabular}{ll}
\hline Plant part & \\
Young leaves & 65 \\
Mature leaves & 3 \\
Ripe and unripe fruits & 31 \\
Seeds and seedpods & $<1$ \\
Flowers and flowerbuds & $<1$ \\
Bark & 1
\end{tabular}

\section{Behaviour}

Feeding

Moving

Resting

Social

Other

\section{Results}

Young leaves (65\%) and fruits (31\%) were the items most frequently consumed by the C. a. ruwenzorii at this field site. Mature leaves comprised only $3 \%$ of the annual diet, and other food items like bark (1\%), flowers $(<1 \%)$, and seeds $(<1 \%)$ were rarely eaten (Table 1$)$. While young leaves were consistently available in large quantities, fruits were most abundant during the dry season (May to August) (Fig. 2a, b). There was a significant positive correlation between the availability of fruits and their consumption (Table 2), and as a result, fruits were the most common item in the diet of the C. a. ruwenzorii in the dry season, as well as in January when there was also little rain (Fig. 2c). Young leaf consumption was not related to availability (Table 2), but young leaves did appear to be the preferred food item when fruits were scarce, and so comprised the bulk of the diet in wetter months (Fig. 2c). Although mature leaves were abundant throughout the year, they tended to be eaten less than would be expected given their availability (Table 2) and were only consumed during the peak wet season (October and November) (Fig. 2c). There was little temporal pattern in the consumption of flowers and flowerbuds, seeds and seedpods, or bark (Fig. 2c).

The colobus monkeys were observed to feed from 20 tree species, 2 shrub species, and several liana species. Only a handful of tree species comprised the bulk of the diet of the C. a. ruwenzorii at this site (Table 3). The most frequently eaten tree species included Maesopsis eminii (24\% of the annual diet), Antiaris toxicaria (19\%), New-
Table 2. Spearman rank correlations between the proportion of each plant part in the monthly diet of Colobus angolensis ruwenzorii and the food availability index for that plant part, that month

\begin{tabular}{lrrl}
\hline \multicolumn{1}{c}{$\rho$} & $Z$ & $\begin{array}{l}\text { MC-approximated } \\
p \text { value }\end{array}$ \\
\hline Flowers and flowerbuds & 0.044 & 0.145 & 1.000 \\
Ripe and unripe fruits & $\mathbf{0 . 6 9 2}$ & $\mathbf{2 . 2 9 6}$ & $\mathbf{0 . 0 1 4}$ \\
Seeds and seedpods & 0.516 & -0.691 & 1.000 \\
Young leaves & -0.028 & -0.093 & 0.936 \\
Mature leaves & -0.574 & -1.904 & 0.052 \\
\hline
\end{tabular}

Because there were many ties in the data sets, we present Monte-Carlo (MC)-approximated $p$ values. Significant relationships are in bold and trends are italicized.

tonia buchananii (4\%), and Pseudospondias microcarpa $(4 \%)$. These species were common in the study area, and after accounting for availability, only $A$. toxicaria and $M$. eminii were highly selected (Table 3 ). The C. a. ruwenzorii ate the fruits, young and mature leaves, and the bark of these two species. Other species were highly selected (i.e., selection ratios $>1$ ), but because they were relatively rare within the study area, they comprised a smaller proportion of the diet: Prunus africana (2\% of the annual diet), Rauvolfia vomitoria $(<1 \%)$, Sapium ellipticum (3\%), and Swietenia macrophylla $(<1 \%)$ (Table 3). None of the consumed tree species were consistently important over time (i.e., consistently comprised more than $1 \%$ of the monthly diet), nor did any one species comprise the majority of their diet in any given month (Table 3). When we look more specifically at preferences for the parts of each species that were consumed, we find that only the fruits and young leaves of some species were preferred (Table 3 ). The fruits of A. toxicaria, M. eminii, P. microcarpa, S. ellipticum, Teclea nobilis, and the seeds of $N$. buchananii were preferred in at least 1 month of the study period. Similarly, C. a. ruwenzorii also showed a preference for the young leaves of A. toxicaria, P. africana, S. ellipticum, and $S$. macrophylla in at least 1 month of the study period. Lianas were an important food resource for the colobus making up 33.7\% of the annual diet (Table 3); however, since they were not represented in the phylogeny survey, we could not assess the extent to which they were selected/preferred.

Forty percent of the annual activity budget was dedicated to resting, $28 \%$ to feeding, $25 \%$ to moving, $7 \%$ to social interactions, and $1 \%$ to other activities (Table 1 ). There was very little temporal variation in the activity
Arseneau-Robar/Changasi/Turner/ Teichroeb 
Fig. 2. a Average daily rainfall ( $\mathrm{mm} /$ day) for each month of the study period. $\mathbf{b}$ Food availability index scores for the different plant parts consumed. c The monthly diet of Colobus angolensis ruwenzorii near Lake Nabugabo, Uganda.

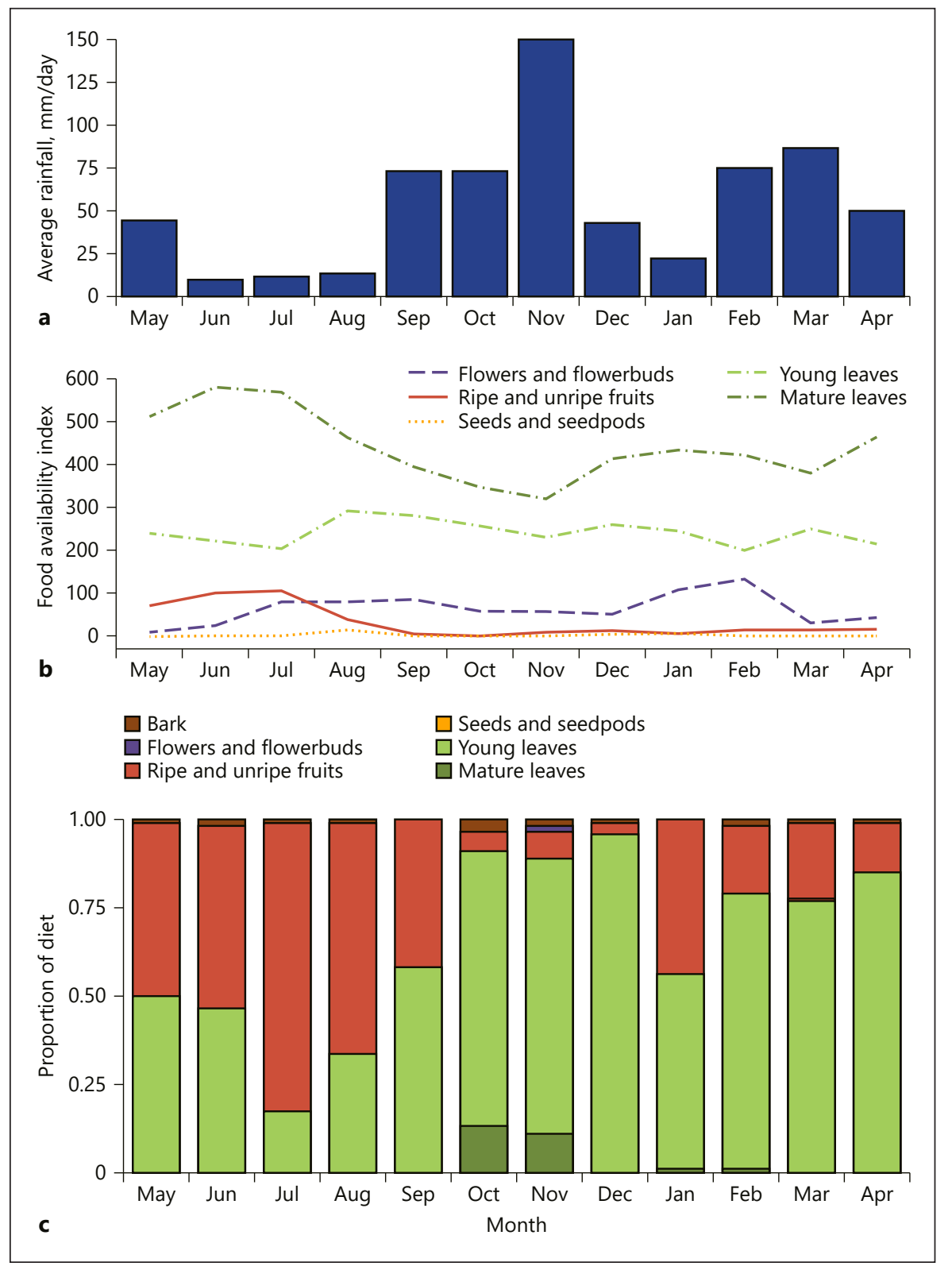

budget of the C. a. ruwenzorii at this site over the year (Fig. 3). September is the only month with a notable change, with a decrease in moving and social behaviour and an increase in feeding and resting coinciding with the switch from more fruit feeding back to more young-leaf feeding.

In assessing the use of fallback foods, we found no significant correlation between the consumption of young leaves and the availability of ripe and unripe fruits, which were the plant parts that were highly selected when available (Spearman: $r_{s}=-0.580, Z=-1.925, p=0.116$ ). How- ever, we did find that mature leaves tended to be consumed when fruits were less available within the forest (Spearman: $r_{s}=-0.603, Z=-2.001, p=0.084$ ). Similarly, mature leaf consumption was significantly negatively correlated with the availability of preferred food items, which included the fruits and/or young leaves of 8 tree species (Spearman: $r_{s}=-0.580, Z=-1.945, p=0.047$ ). Importantly, this fallback food comprised only $3 \%$ of the annual diet (Table 1). Similarly, food items that had low preference scores accounted for only $15 \%$ of the annual diet (Table 3). 
Table 3. The diet of the Colobus angolensis ruwenzorii living near Lake Nabugabo, Uganda, including the species eaten, their proportion in the annual and monthly diet (minimum and maximum proportions), and the selection ratio for each species

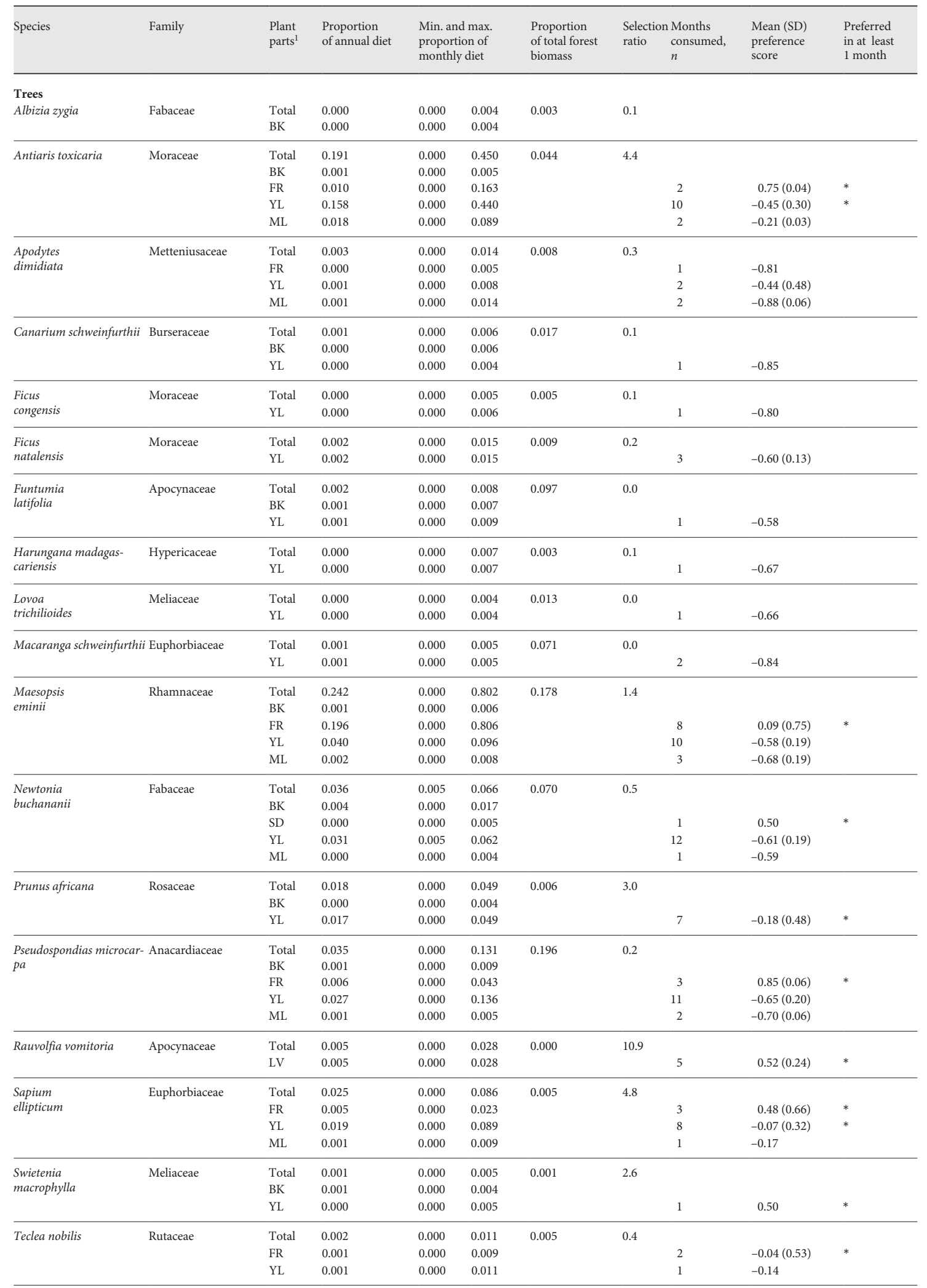


Table 3 (continued)

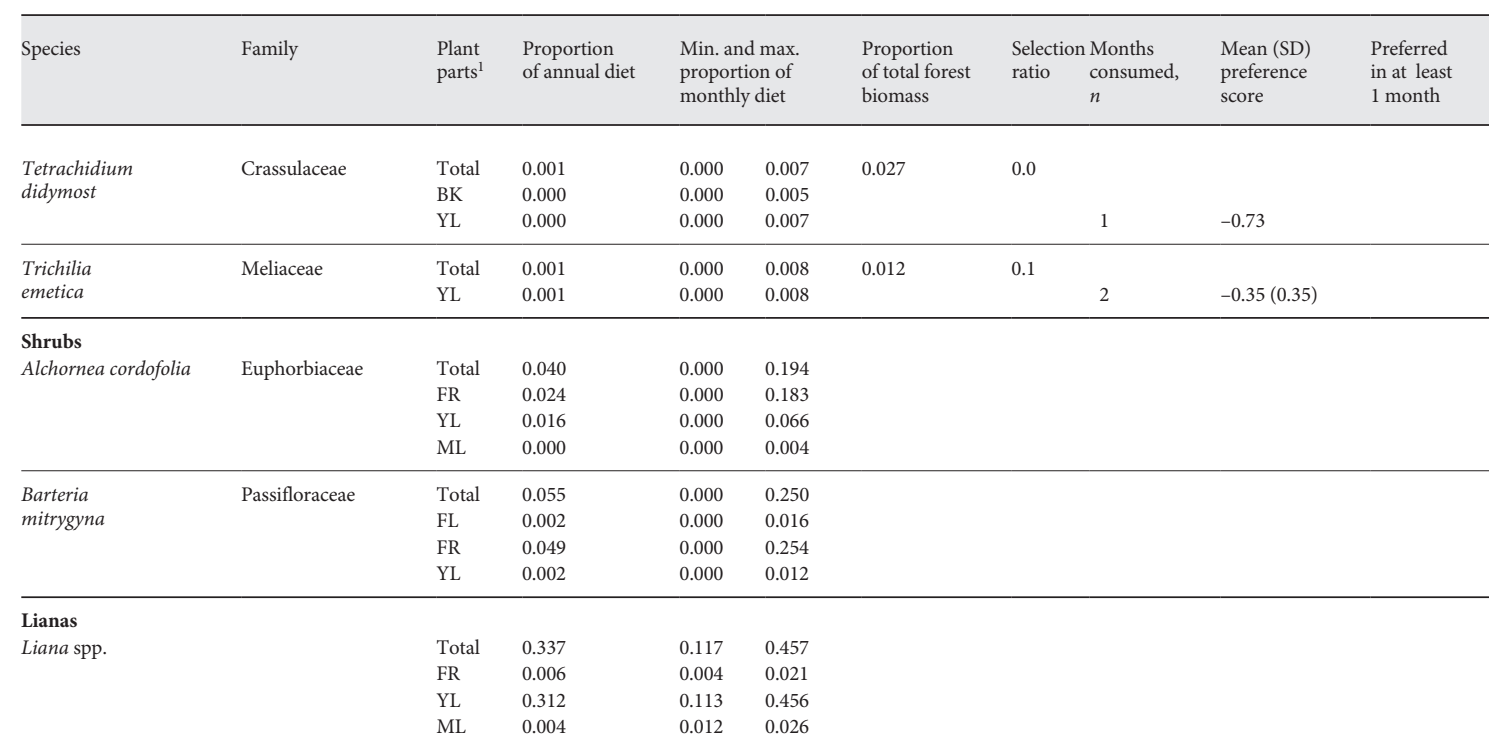

Also included is the prevalence of the various plant parts, from each species, in the annual and monthly diet (minimum and maximum proportions), the number of month each species part was eaten, its mean preference score, and whether it was a preferred food item in at least 1 month of the study period. BK, bark; FL, flowers/flowerbuds; FR, ripe and unripe fruits; SD, seeds and seedpods; YL, young leaves; ML, mature leaves; LV, leaves. Note that shrub and liana species were not included in our ecological or phenology survey, and so lack selection and preference scores.

Fig. 3. Monthly activity budget for Colobus angolensis ruwenzorii near Lake Nabugabo,

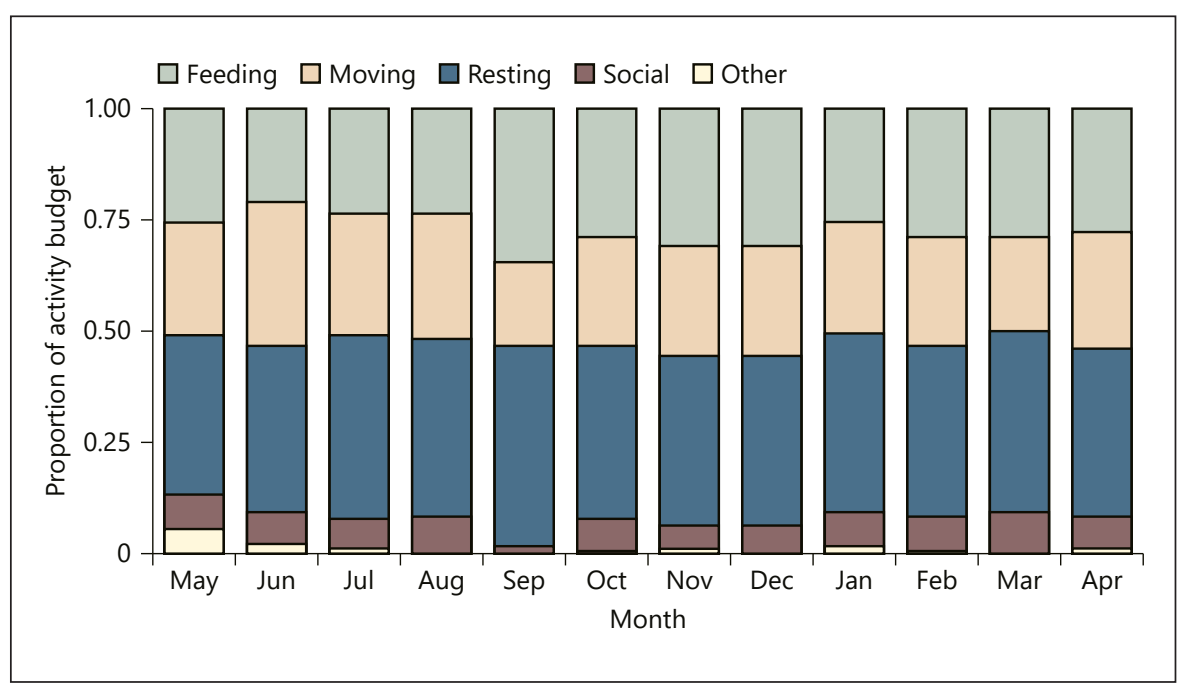

\section{Discussion}

The diet of the C. a. ruwenzorii living at Nabugabo, Uganda, largely consisted of ripe and unripe fruits and young leaves. Fruits were selected when they were available, and both fruits and young leaves of some species were preferred food items. Mature leaf consumption tended to correlate negatively with these selected/pre- ferred food items, suggesting that mature leaves are a fallback food for this population. However, mature leaves comprised a very small proportion of the annual diet, signifying that the C.a. ruwenzorii at this site rely minimally on fallback foods. This is likely because young leaf availability was only slightly lower than mature leaf availability for much of the year, and fruits were seasonally abundant. Furthermore, preferred species parts were 
available throughout the year. These findings suggest that the $C$. a. ruwenzorii living at Nabugabo had access to abundant, high-quality food resources year-round. This high-quality diet likely allowed them to employ an energy maximization foraging strategy, as the observed levels of resting time were comparable to those seen in more frugivorous African colobines and lower than typically observed in more folivorous species [Korstjens et al., 2010; Fashing, 2011]. Their reliance on food items that tend to have a clumped distribution likely explains why cohesion between core units is lower in the Nabugabo population than has been reported elsewhere [Fimbel et al., 2001; Fashing et al., 2007; Miller et al., 2020c].

The observed consumption of young leaves in this study is one of the highest values reported in the African colobines, being higher only in Procolobus verus at Tai National Park [Korstjens et al., 2007], and matched by $C$. guereza at Kibale National Park [Oates, 1977]. Mature leaves were avoided by the $C$. $a$. ruwenzorii at our study site and were only used as a fallback food that the monkeys relied upon to a minimal extent in the wettest months of the year. In this respect, C. a. ruwenzorii at Nabugabo are similar to most other black-and-white colobus populations that show avoidance of mature leaves except during seasonal bottlenecks [Colobus polykomos, Dasilva, 1994; C. satanas, Fleury and Gautier-Hion, 1999; C. guereza, Fashing, 2001a; Wasserman and Chapman, 2003; C. vellerosus, Saj and Sicotte, 2007a, b], with the notable exception of the C. a. ruwenzorii in Nyungwe [Fimbel et al., 2001].

Fruit was significantly positively selected for when it became available, and the fruits of $A$. toxicaria, M. eminii, $P$. microcarpa, S. ellipticum, and T. nobilis (as well as the seeds of $N$. buchananii) were preferred food items in this population. The fruits of M. eminii were particularly important as they comprised $20 \%$ of the annual diet. Colobines are not thought to be able to feed on large quantities of ripe fruit because the high acidity of the fruit flesh can kill the bacteria in the forestomach that aid in the breakdown of cellulose in leaves [Goltenboth, 1976]. To mitigate this, colobus monkeys are often described as feeding on unripe fruits [Fashing, 2011]. As Davies et al. [1999] put it "a colobus fruit can be described as: dull green or brown/black; unripe;

weighing $<50 \mathrm{~g}$; generally lack flesh, but when it is present it is dry or fibrous or both" (p. 345). The fruits of M. eminii and A. toxicaria, as well as the shrub Alchornea cordofolia, fit this description well. Furthermore, for M. eminii fruit, the colobus at Nabugabo often eat off the outer layer of the fruit skin and leave the fleshier parts of the fruit intact. Impor- tantly, M. eminii accounts for $18 \%$ of the total forest biomass, A. toxicaria for $4 \%$, and A. cordofolia is also common. Thus, the high levels of frugivory observed in this study likely occur because the C. a. ruwenzorii at Nabugabo have access to abundant amounts of fruits that they are able to digest, despite being an anatomical folivore, and they are using behavioural strategies for exploiting the available fruit resources to the fullest.

While abundant food resources and behavioural strategies for exploiting them seem to allow the C. a. ruwenzorii to form large groups, scramble competition is very likely an issue in this population, since it has been shown to impact folivorous primates in groups that are comparatively much smaller [e.g., Steenbeek and van Schaik, 2001; Snaith and Chapman, 2008; Teichroeb and Sicotte, 2009]. Adjusting activity budgets is one of the main ways that animals can compensate for increased food competition [Caraco, 1979; Janson, 1988]. However, it has been suggested that folivores may be limited in the degree that they can use this strategy [Borries et al., 2008; Korstjens et al., 2010]. Resting time may be dictated by a high-fibre diet paired with slow digestion that includes fermentation [Lambert, 1998], feeding time may be limited by gut capacity [Stephens and Krebs, 1986], and moving time may be limited by a diet with a low overall energy yield [Janson and Goldsmith, 1995]. If the diet is altered however, to include less fibrous food with more energy available from either carbohydrates or protein, colobus may be able to adjust activity budgets and behave more similarly to a typical energy-maximizing frugivore. Resting times for the C. a. ruwenzorii at Nabugabo (40\%) were among the lowest observed in the African colobines [Fashing et al., 2007] and are most similar to those seen in the more frugivorous red colobus [reviewed in Fashing, 2011]. In support of our second hypothesis, this finding suggests that this population is employing an energy maximization foraging strategy. This strategy is likely possible because of the high-quality resources available. A diet concentrated on young leaves and fruit should result in a relatively low consumption of fibre [Waterman et al., 1980]. Consequently, digestion may not be inhibited as greatly as for those species that eat large quantities of mature leaves [Milton, 1979; Chivers, 1994; Lambert, 1998]. This inference needs to be investigated with more research on the nutritional composition of their foods; however, work in other species has shown that when more energy is available, animals can adjust their time budgets and movement patterns [Godfrey, 2003; Riley, 2007; Dunbar et al., 2009]. The same species can show energy-minimizing or energy-maximizing strategies depending on the quality
44

Folia Primatol 2021;92:35-48 DOI: $10.1159 / 000511046$
Arseneau-Robar/Changasi/Turner/ Teichroeb 
of their current habitat [A. calmitans, Jung et al., 2015; A. pigra, Rangel-Negrín et al., 2018; Klass, 2020; A. palliata mexicana, Asensio et al., 2007; C. djamdjamensis, Mekonnen et al., 2017].

There were important differences in the diet and activity budgets observed in this study, and those observed in previous work on the same subspecies living in Nyungwe National Park, Rwanda. While both populations had access to abundant high-quality resources, the types of resources, and therefore the diets in the two populations of C. a. ruwenzorii, differed greatly. Our study band at Nabugabo relied on young leaves (65\%) and fruits (31\%) while the Nyungwe population relied on fruit less (16\%) and largely consumed lichens [21\%, Miller et al., 2020a] and mature leaves that had high protein-to-fibre ratios [40\%, Fimbel et al., 2001]. We found that the C. a. ruwen$z$ orii at Nabugabo spent less time feeding $(28 \%)$ and more time moving (25\%) than their conspecifics at Nyungwe [Fashing et al., 2007]. These differences in activity budget are likely related to the distribution of each population's important food resources. The large, relatively cohesive supergroups observed at Nyungwe are only possible if food resources are both abundant and uniformly distributed [Wrangham et al., 1993; Janson and Goldsmith, 1995; Janson and van Schaik, 1988]. The large valley bowls at Nyungwe are filled with lianas whose mature leaves are nutritious [Fimbel et al., 2001; Fashing et al., 2007]. Here, the colobus monkeys spend $1-3 \mathrm{~h}$ per day on the ground feeding on these uniformly distributed food resources [A. Miller, pers. commun.]. This "grazing-like" feeding pattern does not require a lot of between-patch movement, which could account for the lower amount of time spent moving and the higher amount of time spent feeding in Nyungwe. To minimize scramble competition, the large band maintains a very large home range $(>20$ $\mathrm{km}^{2}$ compared to the much smaller $<2 \mathrm{~km}^{2}$ observed at Nabugabo) [Fashing et al., 2007; Adams and Teichroeb, 2020] and sometimes migrates large distances to access new food patches [Fashing et al., 2007]. Thus, after exploiting the resources in one area, the band moves on and allows a long regeneration time before returning to the same patch [Fashing et al., 2007]. Maintaining such large groups may be of paramount importance at Nyungwe, since chimpanzees (Pan troglodytes) are present as predators [Fashing et al., 2007].

Conversely, the C. a. ruwenzorii at Nabugabo rely on food resources that are not uniformly distributed. The seasonal flushing of young leaves and fruiting of trees typically leads to a resource base with a clumped distribution [Janson and van Schaik, 1988; Johnson et al., 2002], and even within food patches, young leaves and fruit are typically distributed in clusters near terminal branches [Snaith and Chapman, 2005]. As a result, the colobus here almost always forage in the canopy [Adams and Teichroeb, 2020] and frequently move both between discrete food patches and within food patches. This feeding pattern likely explains the lower time spent feeding and higher time spent moving in Nabugabo versus Nyungwe. It has been commonly observed that time spent moving increases in patchy habitats in both non-primate species [wild turkeys, Meleagris gallopavo silvestris, Marable et al., 2012; wood mice, Apodemus sylvaticus, Corp et al., 1997; racoons, Procyon lotor, Beasley and Rhodes, 2010] and in primates [A. clamitans, Jung et al., 2015; A. pigra, Ostro et al., 1999; Chlorocebus pygerythrus and Erythrocebus patas, Isbell et al., 1998; Lemur catta, Gabriel, 2013]. Importantly, the clumped distribution of resources at Nabugabo (e.g., fruits and young leaves) should result in high levels of scramble competition as group size increases, making it difficult for the large band of C. a. ruwenzorii at Nabugabo to remain cohesive. The fission-fusion social organization observed in this population [Stead and Teichroeb, 2019] appears to be an effective strategy for dealing with scramble competition as it would allow the C.a. ruwenzorii to adjust operational group size to the current abundance and distribution of resources. Supporting this supposition are recent findings that core units are most likely to fuse together into large aggregations when fruit resources are at their most abundant [Adams et al., in review].

Our findings, as well as the findings of others, highlight that C.a. ruwenzorii are able to form extremely large groups when their resource base allows it, but flexibly adjust grouping patterns to changing resource availability and/or distribution. We cannot be certain how generalizable these patterns are across other subspecies of $C$. angolensis, but "supertroops" or aggregations of groups have been observed in multiple studies, suggesting the potential to form large, hierarchically structured groups may be a species-wide trait [e.g., C. a. cottoni, Bocian, 1997; C. $a$. palliata, Moreno-Black and Bent, 1982]. This begs the question of why other species of black-and-white colobus only form groups averaging 4-20 individuals [Fashing, 2011], even when living in high-quality habitats [e.g., C. guereza, Fashing, 2001a; C. polykomos, Dasilva, 1994; Korstjens, 2001], instead of the hundreds of individuals observed in some $C$. angolensis studies. It is possible that predation rates vary for black-and-white colobus populations and that these tend to be higher for $C$. a. ruwenzorii populations providing an incentive for larger group sizes; however, we do not currently have data that suggest this. 
We posit that even when ecology allows large groups to form, social behaviour and reproductive strategies may still keep groups small. The large group sizes observed in C. a. ruwenzorii can only occur when there is a high level of between-unit tolerance, particularly among adult males. In two other species of black-and-white colobus, adult males have been shown to defend important foodrich areas for the females in their group, and these males show little tolerance for nearby conspecific groups [C. vellerosus, Teichroeb et al., 2012; Teichroeb and Sicotte, 2018; C. guereza, Fashing, 2001b; Harris, 2006]. Conversely, it has been anecdotally noted that males in C. angolensis are more tolerant towards males from their own group, as well as extragroup males, than C. guereza [Bocian, 1997]. Therefore, an exciting avenue of future research would be to investigate the form of interunit interactions and male relationships in C. angolensis, including in the Ruwenzori subspecies.

\section{Acknowledgements}

We are grateful to Edward Mujjuzi, Hannington Kakeeto, Matovu Ponsiano, Dr. Dennis Twinomugisha, Dr. Colin Chapman, and Dr. Lauren Chapman for assistance in the field. We thank three anonymous reviewers for their comments that helped improve the paper.

\section{Statement of Ethics}

This study adhered to the Code of Best Practice for Field Primatology, and ethics approval for the research was given by the Uganda National Council of Science and Technology (permit No. NS537), the Uganda Wildlife Authority (permit No. UWA/ $\mathrm{TDO} / 33 / 02$ ), and the University of Toronto Animal Care Committee (permit No. 20011416).

\section{Conflict of Interest Statement}

The authors have no conflicts of interest to declare.

\section{Funding Sources}

Funding was provided by a Natural Science and Engineering Council of Canada Discovery Grant to J. Teichroeb (RGPIN-2016-06321).

\section{Author Contributions}

Julie Teichroeb organized, funded, and managed field data collection. Amtul Changasi and Evan Turner entered data and aided with data analyses. T. Jean Arseneau-Robar did the majority of the data analyses. Julie Teichroeb and T. Jean Arseneau-Robar wrote the manuscript with input from Amtul Changasi and Evan Turner.

\section{References}

Adams FV, Arseneau-Robar TJM, Bonnell TR, Stead SM, Teichroeb JA (in review). Temporal patterns in the social network of core units in Rwenzori Angolan colobus monkeys: effects of food availability and inter-unit dispersal. Ecology and Evolution.

Adams FV, Teichroeb JA (2020). Microhabitat use in Angolan colobus monkeys (Colobus angolensis ruwenzorii) at Nabugabo, Uganda, demonstrates intraspecific variability. International Journal of Primatology 41: 24-44.

Altmann J (1974). Observational study of behavior: sampling methods. Behaviour 49: 227 266.

Altmann SA (1991). Diets of yearling female primates (Papio cynocephalus) predict lifetime fitness. Proceedings of the National Academy of Sciences of the United States of America 88: 420-423.

Altmann SA (1998). Foraging for Survival: Yearling Baboons in Africa. Chicago, University of Chicago Press.

Ankel-Simons F (2007). Primate Anatomy: An Introduction, 3rd ed. Burlington, Academic Press.

Arseneau-Robar TJM, Joyce MM, Stead SM, Teichroeb JA (2018). Proximity and grooming patterns reveal opposite-sex bonding in Rwenzori Angolan colobus monkeys (Colobus angolensis ruwenzorii). Primates 59: 267279.

Asensio N, Cristobal-Azkarate J, Américo P, Dias D, Vea JJ, Rodríguez-Luna E (2007). Foraging habits of Alouatta palliata mexicana in three forest fragments. Folia Primatologica 78: 141153.

Bauchop T, Martucci RW (1968). Ruminant-like digestion of the langur monkey. Science 161: 698-700.

Beasley JC, Rhodes OE (2010). Influence of patchand landscape-level attributes on the movement behavior of raccoons in agriculturally fragmented landscapes. Canadian Journal of Zoology 88: 161-169.

Bocian CM (1997). Niche Separation of Blackand-White Colobus Monkeys (Colobus angolensis and Colobus guereza) in the Ituri Forest (Zaire). PhD dissertation, New York University.

Borries C, Larney E, Lu A, Ossi K, Koenig A (2008). Costs of group size: lower developmental and reproductive rates in larger groups of leaf monkeys. Behavioral Ecology 19: 1186-1191.
Caraco T (1979). Time budgeting and group size: a test of theory. Ecology 60: 618-627.

Chapman CA, Chapman LJ (1990). Dietary variability in primate populations. Primates 31: 121-128.

Chapman CA, Rothman JM, Lambert JE (2012) Food as a selective force in primates. In The Evolution of Primate Societies (Mitani JC, Call J, Kappeler PM, Palombit RA, Silk JB, eds.), pp 149-168. Chicago, University of Chicago Press.

Chapman CA, Twinomugisha D, Teichroeb JA, Valenta K, Sengupta R, Sarkar D, et al (2016). How do primates survive among humans? Mechanisms employed by vervet monkeys at Lake Nabugabo, Uganda. In Ethnoprimatology: Primate Conservation in the 21st Century (Waller MT, ed.), pp 77-94. Cham, Springer International Publishing.

Chivers D (1994). Functional anatomy of the gastrointestinal tract. In Colobine Monkeys: Their Ecology, Behaviour and Evolution (Davies G, Oates J, eds.), pp 205-228. Cambridge, Cambridge University Press.

Clutton-Brock TH, Harvey PH (1977). Primate ecology and social organization. Journal of Zoology London 183: 1-39.
46

Folia Primatol 2021;92:35-48

DOI: 10.1159/000511046
Arseneau-Robar/Changasi/Turner/

Teichroeb 
Coley PD, Barone JA (1996). Herbivory and plant defenses in tropical forests. Annual Review of Ecology and Systematics 27: 305-335.

Corp N, Gorman ML, Speakman JR (1997). Ranging behaviour and time budgets of male wood mice Apodemus sylvaticus in different habitats and seasons. Oecologia 109: 242-250.

Dasilva GL (1992). The western black-and-white colobus as a low-energy strategist: activity budgets, energy expenditure and energy intake. Journal of Animal Ecology 61: 79-91.

Dasilva GL (1994). Diet of Colobus polykomos on Tiwai Island: selection of food in relation to its seasonal abundance and nutritional quality. International Journal of Primatology 15: 655-680.

Davies AG, Oates JF, Dasilva GL (1999). Patterns of frugivory in three west African colobine monkeys. International Journal of Primatology 20: 327-357.

Doran-Sheehy D, Mongo P, Lodwick J, ConklinBrittain NL (2009). Male and female western gorilla diet: preferred foods, use of fallback resources, and implications for ape versus old world monkey foraging strategies. American Journal of Physical Anthropology 140: 727-738.

Dunbar RIM (1992). Time: a hidden constraint on the behavioural ecology of baboons. Behavioral Ecology and Sociobiology 31: 35-49.

Dunbar RIM, Korstjens AH, Lehmann J (2009). Time as an ecological constraint. Biological Reviews 84: 413-429.

Emlen JM (1966). The role of time and energy in food preference. American Naturalist 100: 611-617.

Fashing PJ (2001a). Feeding ecology of guerezas in the Kakamega Forest, Kenya: the importance of Moraceae fruit in their diet. International Journal of Primatology 22: 579-609.

Fashing PJ (2001b). Male and female strategies during intergroup encounters in guerezas (Colobus guereza): evidence for resource defense mediated through males and a comparison with other primates. Behavioral Ecology and Sociobiology 50: 219-230.

Fashing PJ (2011). African colobine monkeys: their behavior, ecology, and conservation. In Primates in Perspective (Campbell CJ, Fuentes A, MacKinnon KC, Bearder SK, Stumpf RM, eds.), 2nd ed., pp 203-229. New York, Oxford University Press.

Fashing PJ, Mulindahabi F, Gakima JB, Masozera M, Mununura I, Plumptre AJ, et al (2007). Activity and ranging patterns of Colobus angolensis ruwenzorii in Nyungwe forest, Rwanda: possible costs of large group size. International Journal of Primatology 28: 529-550.

Felton AM, Felton A, Lindenmayer DB, Foley WJ (2009). Nutritional goals of wild primates. Functional Ecology 23: 70-78.

Field A, Miles J, Field Z (2012). Discovering Statistics Using R. London, SAGE Publications.

Fimbel C, Vedder A, Dierenfeld E, Mulindahabi F (2001). An ecological basis for large group size in Colobus angolensis in the Nyungwe Forest, Rwanda. African Journal of Ecology 39: $83-92$.
Fleury M, Gautier-Hion A (1999). Seminomadic ranging in a population of black colobus ( $\mathrm{Col}$ obus satanas) in Gabon and its ecological correlates. International Journal of Primatology 20: 491-509.

Gabriel DN (2013). Habitat use and activity patterns as an indication of fragment quality in a strepsirrhine primate. International Journal of Primatology 34: 388-406.

Ganas J, Ortmann S, Robbins MM (2008). Food preferences of wild mountain gorillas. American Journal of Primatology 70: 927-938.

Ganzhorn JU (1988). Food partitioning among Malagasy primates. Oecologia 75: 436-450.

Ganzhorn JU, Arrigo-Nelson SJ, Carrai V, Chalise MK, Donati G, Droescher I, et al (2017). The importance of protein in leaf selection of folivorous primates. American Journal of Primatology 79: e22550.

Garber PA (1987). Foraging strategies among living primates. Annual Review of Anthropology 16: 339-364.

Godfrey JD (2003). Potential use of energy expenditure of individual birds to assess quality of their habitats. In Conservation Applications of Measuring Energy Expenditure of New Zealand Birds: Assessing Habitat Quality and Costs of Carrying Radio Transmitters (Williams M, ed.), p 95. Wellington, Science for Conservation.

Goltenboth R (1976). Nonhuman primates (apes, monkeys and prosimians). In The Handbook of Zoo Medicine (Kloes HG, Lang EM, eds.), pp 46-85. New York, van Norstrand Reinhold Co.

Griffiths DW (1986). The inhibition of digestive enzymes by polyphenolic compounds. Advances in Experimental Medicine and Biology 199: 509-516.

Grueter CC, Li D, Ren B, Wei F, Xiang Z, Van Schaik CP (2009). Fallback foods of temperate-living primates: a case study on snubnosed monkeys. American Journal of Physical Anthropology 140: 700-715.

Hájek J, Šidák Z, Sen PK (1999). Theory of Rank Tests. San Diego, Academic Press.

Harris TR (2006). Between-group contest competition for food in a highly folivorous population of black and white colobus monkeys (Colobus guereza). Behavioral Ecology and Sociobiology 61: 317-329.

Hothorn T, Hornik K, van de Wiel MA, Zeileis A (2006). A lego system for conditional inference. American Statistician 60: 257-263.

Isbell LA (1991). Contest and scramble competition: patterns of female aggression and ranging behavior among primates. Behavioral Ecology 2: 143-155.

Isbell L, Pruetz JD, Young TP (1998). Movements of vervets (Cercopithecus aethiops) and patas monkeys (Erithrocebus patas) as estimators of food resource size, density, and distribution. Behavioral Ecology and Sociobiology 42: 123133.
Janson CH (1988). Food competition in brown capuchin monkeys (Cebus apella): quantitative effects of group size and tree productivity. Behaviour 105: 53-76.

Janson CH, Goldsmith ML (1995). Predicting group-size in primates - foraging costs and predation risks. Behavioral Ecology 6: 326336.

Janson CH, van Schaik CP (1988). Recognizing the many faces of primate food competition: methods. Behaviour 105: 165-186.

Johnson D, Kays R, Blackwell P, Macdonald D (2002). Does the resource dispersion hypothesis explain group living? Trends in Ecology and Evolution 17: 563-570.

Jung L, Mourthe I, Grelle C, Strier K, Boubli J (2015). Effects of local habitat variation on the behavioral ecology of two sympatric groups of brown howler monkey (Alouatta clamitans). PLoS One 10: e0129789.

Kappeler PM, van Schaik CP (2002). Evolution of primate social systems. International Journal of Primatology 23: 707-740.

Kay RNB, Davies AG (1994). Digestive physiology. In Colobine Monkeys: Their Ecology, Behaviour and Evolution (Davies AG, Oates JF, eds.), pp 229-250. Cambridge, Cambridge University Press.

Klass KM (2020). Black Howler Monkey (Alouatta pigra) Demography and Behaviour in Unprotected Forest Fragments around Palenque $\mathrm{Na}$ tional Park, Mexico. PhD dissertation, University of Toronto.

Korstjens AH (2001). The Mob, the Secret Sorority, and the Phantoms. An analysis of the SocioEcological Strategies of the Three Colobines of Tai. PhD dissertation, Utrecht University.

Korstjens AH, Bergmann K, Deffernez C, Krebs M, Nijssen EC, van Oirschot BAM, et al (2007). How small-scale differences in food competition lead to different social systems in three closely related sympatric colobines. In The Monkeys of the Taï Forest, Ivory Coast: An African Primate Community (McGraw S, Zuberbühler K, Noë R, eds.), pp 72-108. Cambridge, Cambridge University Press.

Korstjens AH, Dunbar RIM (2007). Time constraints limit group sizes and distribution in red and black-and-white colobus. International Journal of Primatology 28: 551-575.

Korstjens AH, Lehmann J, Dunbar RIM (2010). Resting time as an ecological constraint on primate biogeography. Animal Behavior 79: 361-374.

Kumpan LT, Rothman JM, Chapman CA, Teichroeb JA (2019). Playing it safe? Solitary vervet monkeys (Chlorocebus pygerythrus) choose high-quality foods more than those in competition. American Journal of Primatology 81: e23002.

Lambert JE (1998). Primate digestion: interactions among anatomy, physiology, and feeding ecology. Evolutionary Anthropology 7: $8-20$. 
Lambert JE, Rothman JM (2015). Fallback foods, optimal diets, and nutritional targets: primate responses to varying food availability and quality. Annual Review of Anthropology 44: 493-512.

Liu X, Stanford C, Yang J, Yao H, Li Y (2013). Foods eaten by the Sichuan snub-nosed monkey (Rhinopithecus roxellana) in Shennongjia National Nature Reserve, China, in relation to nutritional chemistry. American Journal of Primatology 75: 860-871.

Marable M, Belant J, Godwin D, Wang G (2012). Effects of resource dispersion and site familiarity on movements of translocated wild turkeys on fragmented landscapes. Behavioral Processes 91: 119-124.

Mekonnen A, Fashing PJ, Bekele A, HernandezAguilar RA, Rueness EK, Nguyen N, et al (2017). Impacts of habitat loss and fragmentation on the activity budget, ranging ecology and habitat use of Bale monkeys (Chlorocebus djamdjamensis) in the southern Ethiopian Highlands. American Journal of Primatology 79: 1-13.

Miller A, Judge D, Uwingeneye G, Ndayishimiye D, Grueter CC (2020a). Diet and use of fallback foods by Rwenzori black-and-white colobus (Colobus angolensis ruwenzorii) in Rwanda: implications for supergroup formation. International Journal of Primatology 41: 434-457.

Miller A, Judge DS, Uwingeneye G, Ndayishimiye D, Kaplin BA, Grueter CC (2020b). Feeding competition inferred from patch depletion in a supergroup of Rwenzori black-and-white colobus monkey (Colobus angolensis ruwenzorii) in Rwanda. Behaviour 157: 731-760.

Miller A, Uddin S, Judge DS, Kaplin BA, Ndayishimiye D, Uwingeneye G, Grueter CC (2020c). Spatiotemporal association patterns in a supergroup of Rwenzori black-and-white colobus (Colobus angolensis ruwenzorii) are consistent with a multilevel society. American Journal of Primatology 82: e23127.

Milton K (1979). Factors influencing leaf choice by howler monkeys: a test of some hypotheses of food selection by generalist herbivores. American Naturalist 114: 362-378.

Milton K (1999) Nutritional characteristics of wild primate foods: do the diets of our closest living relatives have lessons for us? Nutrition 15: 488-498.

Moreno-Black GS, Bent EF (1982). Secondary compounds in the diet of Colobus angolensis. African Journal of Ecology 20: 29-36.

Nature Conservation (2006). Measurement of diameter at breast height (DBH). https://www. afcd.gov.hk/english/conservation/con_tech/ files/common/NCPN_No.02_measurement of_DBH_ver.2006.pdf.

Oates JF (1977). The guereza and its food. In Primate Ecology: Studies of Feeding and Ranging Behavior in Lemurs, Monkeys and Apes (Clutton-Brock TH, ed.), pp 419-467. London, Academic Press.
Oates JF (1988). The diet of the olive colobus monkey, Procolobus verus, in Sierra Leone. International Journal of Primatology 9: 457-478.

Ostro L, Silver S, Koontz F, Young T, Horwich R (1999). Ranging behavior of translocated and established groups of black howler monkeys Alouatta pigra in Belize, Central America. Biological Conservation 87: 181-190.

Rangel-Negrín A, Coyohua-Fuentes A, CanalesEspinosa D, Dias PAD (2018). The influence of leaf consumption on time allocation in black howler monkeys (Alouatta pigra). Folia Primatologica 89: 111-122.

R Core Team (2017). R: a language and environment for statistical computing. R Foundation for Statistical Computing, Vienna, Austria. https://www.r-project.org/.

Riley EP (2007). Flexibility in diet and activity patterns of Macaca tonkeana in response to anthropogenic habitat alteration. International Journal of Primatology 28: 107-133.

Rosenberger AL, Strier KB (1989). Adaptive radiation of the ateline primates. Journal of $\mathrm{Hu}$ man Evolution 18: 717-750.

R Studio Team (2020). RStudio: integrated development for R. RStudio, PBC, Boston, MA. http://www.rstudio.com/.

de Sá RM, Strier KB (1992). A preliminary comparison of forest structure and use by two isolated groups of woolly spider monkeys, Brachyteles arachnoides. Biotropica 24: 45559.

Saj TL, Sicotte P (2007a). Predicting the competitive regime of female Colobus vellerosus from the distribution of food resources. International Journal of Primatology 28: 315-336.

Saj TL, Sicotte P (2007b). Scramble competition among Colobus vellerosus at Boabeng-Fiema, Ghana. International Journal of Primatology 28: 337-355.

Schoener TW (1971). Theory of feeding strategies. Annual Review of Ecology and Systematics 2: 369-404.

Snaith TV, Chapman CA (2005). Towards an ecological solution to the folivore paradox: patch depletion as an indicator of within-group scramble competition in red colobus monkeys (Piliocolobus tephrosceles). Behavioral Ecology and Sociobiology 59: 185-190.

Snaith TV, Chapman CA (2008). Red colobus monkeys display alternative behavioral responses to the costs of scramble competition. Behavioral Ecology 19: 1289-1296.

Stead SM, Teichroeb JA (2019). A multi-level society comprised of one-male and multi-male core units in an African colobine (Colobus angolensis ruwenzorii). PLoS One 14: 0217666.

Steenbeek R, van Schaik CP (2001). Competition and group size in Thomas's langurs (Presbytis thomasi): the folivore paradox revisited. Behavioral Ecology and Sociobiology 49: 100-110.

Stephens D, Krebs J (1986). Foraging Theory. Princeton, Princeton University Press.

Strier KB (1992). Atelinae adaptations: behavioral strategies and ecological constraints. American Journal of Physical Anthropology 88: 515524.
Struhsaker TT (1975). The Red Colobus Monkey. Chicago, University of Chicago Press.

Sun C, Kaplin B, Kristensen K, et al (1996). Tree phenology in a tropical montane forest in Rwanda. Biotropica 28: 668-681.

Teichroeb JA, Bridgett GR, Corriveau A, Twinomugisha D (2019). The immediate impact of selective logging on Rwenzori Angolan colobus (Colobus angolensis ruwenzorii) at Lake Nabugabo, Uganda. In Primate Research and Conservation in the Anthropocene (Ehie MA, Teichroeb JA, Malone N, eds.), pp 120-140. Cambridge, Cambridge University Press.

Teichroeb JA, Sicotte P (2009). Test of the ecological-constraints model on ursine colobus monkeys (Colobus vellerosus) in Ghana. American Journal of Primatology 71: 49-59.

Teichroeb JA, Sicotte P (2018). Cascading competition: the seasonal strength of scramble influences between-group contest in a folivorous primate. Behavioral Ecology and Sociobiology 72: 1-16.

Teichroeb JA, Wikberg EC, Badescu I, MacDonald LJ, Sicotte P (2012). Infanticide risk and male quality influence optimal group composition for Colobus vellerosus. Behavioral Ecology 23: 1348-1359.

Wasserman MD, Chapman CA (2003). Determinants of colobine monkey abundance: the importance of food energy, protein and fibre content. Journal of Animal Ecology 72: 650659 .

Waterman PG (1984). Food acquisition and processing as a function of plant chemistry. In Food Acquisition and Processing in Primates (Chivers DJ, Wood BA, Bilsborough A, eds.), pp 177-211. New York, Springer US.

Waterman PG, Kool KM (1994). Colobine food selection and plant chemistry. In Colobine Monkeys: Their Ecology, Behaviour and Evolution (Davies AG, Oates JF, eds.), pp 251284. Cambridge, Cambridge University Press. Waterman PG, Mbi CN, McKey DB, Gartlan JS (1980). African rainforest vegetation and rumen microbes: phenolic compounds and nutrients as correlates of digestibility. Oecologia 47: 22-33.

Watts DP (1984). Composition and variability of mountain gorilla diets in the central Virungas. American Journal of Primatology 74: 323 356.

Wrangham RW (1980). An ecological model of female-bonded primate groups. Behaviour 75: 262-300.

Wrangham RW, Gittleman JL, Chapman CA (1993). Constraints on group-size in primates and carnivores - population-density and dayrange as assays of exploitation competition. Behavioral Ecology and Sociobiology 32: 199209.

Wrangham R, White FJ (1988). Feeding competition and patch size in the chimpanzee species Pan paniscus and Pan troglodytes. Behaviour 105: 148-162.

Arseneau-Robar/Changasi/Turner/

Teichroeb 